\title{
PEMETAAN KONSUMEN MITRA10 PASAR BARU TANGERANG DARI SISI SEGMENTASI PSIKOGRAFIS
}

\author{
Suhendar Janamarta ${ }^{1}$ \\ ${ }^{1}$ Universitas Buddhi Dharma (Program Studi Manajemen, Fakultas Bisnis) \\ alangkarano@gmail.com
}

\begin{abstract}
ABSTRAK
Segmentasi psikografis menjadi salah satu bagian dari kesinambungan sebuah capaian target dalam dunia pasar guna memasarkan produk yang sama kepada konsumen yang beragam. Tujuan penelitian ini untuk memetakan persepsi yang kemungkinan muncul pada kelompok konsumen yang datang ke Mitra10 Pasar Baru, Kota Tangerang, dengan adanya pemetaan kelompok konsumen ini diharapkan dapat memberikan salah satu gambaran penting terkait persepsi yang muncul pada para konsumen yang datang ke Mitra10, sehingga gambaran tersebut mampu menjadi sebuah kesimpulan bagi pihak manajemen untuk menentukan langkah atau kebijakan yang bisa dilakukan untuk memaksimalkan capaian target pangsa pasar yang sudah ada. Untuk mendapatkan kelompok pemetaan tersebut, peneliti menggunakan teknik analisis klaster dengan memberikan angket kepada 134 responden yang dijadikan sebagai sampel dengan teknik aksidental selama kurang lebih 2 bulan lamanya. Dari hasil olahan data, dapat disimpulkan bahwa setidaknya terdapat 4 klaster atau segmentasi dari konsumen Mitra10 yang terbentuk dari hasil rata-rata. Dengan demikian Pihak manajemen Mitra10 diharapkan mampu membentuk pangsa pasar dengan alternative klaster yang memiliki nilai dominan ditiap kelompoknya sehingga Mitra10 dapat lebih mampu menargetkan konsumen dan mempertahankan kegiatan bisnisnya dimasa pandemic saat ini.
\end{abstract}

Kata Kunci: analisa klaster, segmentasi psikografis

\begin{abstract}
Psychographic segmentation is one part of the continuity of a target in the market world to market the same products to diverse consumers. The purpose of this research to map perceptions that are likely to emerge in consumer groups that come to Mitra10 Pasar Baru, Tangerang City, with the mapping of this consumer group is expected to provide one of the important images related to perceptions that arise in consumers who come to Mitra10, so that the picture can be a conclusion for management to determine the steps or policies that can be done to maximize the reach of existing market share targets. To obtain the mapping group, researchers used cluster analysis techniques by providing questionnaires to 134 respondents who were sampled with axial techniques for approximately 2 months. From the processed data, it can be concluded that there are at least 4 clusters or segmentations from Mitra 10 consumers formed from the average result. Thus, Mitra10 management can target segments with the largest number of cluster members so that Mitra10 can better target consumers and maintain its business activities during the current pandemic.
\end{abstract}

Keywords: analysis cluster, segmentation psicographic 


\section{A. PENDAhuluan}

Masalah penelitian yang diutamakan dalam penelitian ini adalah berdasarkan pada analisa yang dilakukan melalui vosviewer dengan menggunakan data penelitian sebanyak 527 paper terkait dengan karakteristik konsumen yang dikaitkan dengan segmentasi, hal ini terlihat pada gambar 1. Masalah penelitian (research gap) yang dilakukan sebelumnya.

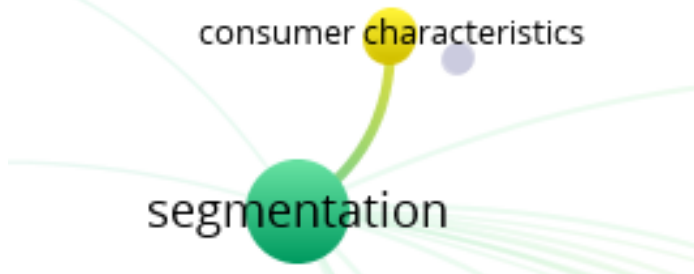

\section{Gambar 1. Masalah Penelitian}

Seperti yang kita ketahui, peningkatan kebutuhan akan tempat kuliah, perkantoran dan fasilitas publik lainnya mendorong dan sejalan dengan peningkatan kebutuhan akan bahan dan perkakas untuk membangun dan melengkapi tempat kuliah, perkantoran dan fasilitas publik tersebut. Oleh karena itu, tidak heran jika saat ini banyak sekali supermarket yang didirikan untuk menjawab kebutuhan tersebut, salah satunya adalah Mitra10. Sejarah menyebutkan (mitra10_official, 2015) bahwa bisnis Mitra10 berawal dari sebuah toko cat kecil yang didirikan pada tahun 1966 di kawasan Bilangan Jakarta. Tata kelola manajemen yang baik mampu membuat perusahaan bergerak kearah perkembangan, system tata kelola manajemen yang mengadopsi konsep modernisasi mampu membentuk PT. Catur Sentosa Adiprana yang merupakan cikal bakal Mitra10 kearah yang mengalami pertumbuhan cashflow yang baik dan membentuk brand di pangsa pasar sebagai salah satu usaha yang bergerak cukup sukses pada bahan bangunan dan perkakas Di Indonesia (Ahmadi \& Herlina, 2017).

Sebagai salah satu jenis usaha yang sedang mengalami perkembangan yang cukup terarah, Mitra10 melakukan pelebaran sayap kedalam sector yang lebih luas dan modern dengan menjalin kerjasama antar jaringan dan mitra dari penyedia brand yang sebelumnya sudah bergerak dibidang bahan bangunan dan perkakas, oleh karena itu, kini Mitra10 dipandang sebagai supermarket yang memiliki kekhususan didalam menjual produk bahan bangunan yang paling dikenal masyarakat. Kini, Supermarket yang memakai brand Mitra10 ini merupakan supermarket bahan bangunan terbesar yang setidaknya hingga kini telah memiliki cabang usaha sejenis yang telah tersebar tidak hanya dikota-kota besar namun juga provinsi-provinsi yang memiliki daya minat pasar yang cukup kuat. Berkonsep mewujudkan bahan bangunan, Mitra10 mengedapankan experience belanja yang nyaman, dan selalu mengenang di hati konsumen, display yang menarik, pelayanan yang ramah, serta program one stop shopping bahan bangunan dan perlengkapan rumah tangga. Di tengah situasi pandemic corona seperti sekarang ini, hampir 
semua bentuk jenis usaha dan perdangan mengalami imbas yang cukup parah, banyak industry dibidang ini gulung tikar satu persatu dan perusahaan lainnya berusaha mencari alternative kebijakan agar perusahaannya dapat bertahan dalam menghadapi gelombang pandemic seperti saat ini. Hal ini juga dirasakan oleh manajemen Mitra10 yang telah membuat beberapa persiapan untuk mempertahankan peluang bisnis agar tidak mengalami kesulitan hingga kebangkrutan terutama di masa new normal, yang dimulai dengan mengalihkan promosi ke iklan digital hingga mengganti strategi pemasaran untuk menmpertahankan pangsa pasar yang telah ada.

Mempertahankan bisnis ditengah pandemic kali ini, sama dengan jenis usaha bisnis lainnya sama-sama membutuhkan yang namanya strategi baru yang belum menggunakan atau memaksimal media social dala memasarkan bisnis yang sedang dikerjakan. Dengan memanfaatkan dan memaksimalkan media social dapat membantu atau memnimalisir pendapatan yang menurun di tengah pembatasan social berskala besar. Selain menggunakan media social dalam memasarkan produk yang dijulan, Mitra10 juga memerlukan adanya usaha untuk memperhatikan pelayanan dan juga empati, tidak hanya sekedar memberikan pelayanan yang baik, namun juga meningkatkan pelayanan untuk memberikan informasi dari keadaan terkini dengan memberikan konten edukasi, hiburan maupun optimisme dan tidak lupa untuk mengadakan program berbagi. Mitra10 Pasar Baru Tangerang juga mengembangkan pendekatan consumer, yakni sebuah pendekatan yang diambil oleh manajemen perusahaan, dalam hal ini mengarah pada manajemen Mitra10 untuk bisa memberikan berbagai alternative apa saja yang terkait atau setidaknya yang dibutuhkan oleh konsumen atau pelanggan sehingga memungkinkan dapat terbentukya persepsi atas keputusan pembelian (Tohari, 2016). Pendekatan jenis ini sangat diutamakan oleh manajemen Mitra10 untuk dijalankan ditiap cabangnya mengingat Mitra10 sendiri selalu dilengkapi dengan sarana gedung yang cukup luas, sehingga mampu mengumpulkan beragam brand dari produk yang memiliki varian berbeda didalam satu sarana gedung tersebut tanpa membuat para konsumen atau pelanggan merasa direpotkan karena masalah teknis ini, sehingga dengan demikian Mitra10 mampu menciptakan keberadaannya semakin dibutuhkan, hal ini mempunyai keuntungan tersendiri dimana jenisa usaha/perusahaan lain mengalami penurunan pendapatan, namun Mitra10 masih menjadi pusat perbelanjaan khusus kebutuhan bahan bangunan dan perkakas yang menguntungkan.

Mitra10 membutuhkan sebuah langkahlangkah strategic dalam mengemas proses pemasaran yang mungkin bisa diaplikasikan dalam berbagai kondisi pasar yang memiliki sifat dinamis seperti saat ini, saat dimana masa pandemic global yang dialami hampir diseluruh dunia, hal mendasar yang paling sering bisa 
diamati adalah dari segi pengelompokan yang memiliki beragam factor atau variable didalamnya (Trisnawati, Suroso, \& Kumorohadi, 2012). Meskipun variable geografis dan demografi secara tradisional menjadi variable utama dalam segmentasi pasar(Prasetyo, Moniharapon, \& Loindong, 2017), namun segmentasi dalam variable psikografis juga patut dilakukan pertimbangan, mengingat didalam segmentasi jenis ini, kita dapat melihat secara penjabarannya bahwa setidaknya terdapat beberapa variable seperti sekumpulan kelas social yang terbentuk dan turunan lainnya dalam hal psikografis layaknya sebuah infikator gaya hidup dan karakteristik konsumen dan pelanggan untuk merespons suatu produk ataupun jasa (Umar, 2000).

Secara harfiah, segmentasi atau segmentation memiliki pengertian pengelompokan, pembagian kepada ruas-ruas, atay pengkelasan (Deviany Amanda Rizki, 2013), lebih lanjut dalam pemasaran itu sendiri telah berkembang sedemikian rupa berbagai aliran yang membentuk saluran pemasaran seperti tidak hanya terletak pada sebuah segmentation yang terbentuk melainkan juga pada proses menargetkan serta mampu membentuk ciitra positioning produk atau jasa yang tersedia di mitra10. Dalam proses yang lebih lanjut, ternyata pengelompokan yang terbentuk itu akan selalu menjadi modal atau sumber kekuatan pertama manajemen Mitra10 untuk memetakan tingkatan konsumen mana yang akan menjadi arah atau focus penjualan sehingga mampu membentuk ciri khas atau keunikan yang dimiliki oleh para konsumen Mitra10 yang dikaitkan pada beragamnya aspek pemasaran khususnya dalam lingkup bauran itu sendiri (Kotler \& Armstrong, 2008).

Penelitian ini bertujuan untuk memberikan hasil pemetaan konsumen Mitra10 terhadap berdasarkan pada segmentasi psikografis sehingga manajemen Mitra10 Pasar Baru Tangerang dapat lebih terencaan dan focus kepada hal memasarkan produk kepada konsumen yang dipilih, selain itu dengan dilakukan pemetaan segmentasi psikografis juga diharapkan mampu memberikan opini atau referensi yang jelas kepada manajemen Mitra10 secara generalisasi sehingga membentuk semacam persiapan yang baik dalam menghadapi persaingan yang mungkin saja muncul tidak hanya pada competitor melainkan dari pihak konsumen itu sendiri (Malhotra, 2006)

\section{B. METODE}

Metode pengelompokan hirarki pada penelitian ini seringkali dijadikan sebagai sebuah metode analisis data dengan harapan mampu membuat sebuah simpulan alternative dari sebuah kelompok klaster yang memiliki kesamaan dari sudut pandang sifatnya (Ketherin, Arifiyanti, Sodik, \& Institut Teknologi Adhi Tama Surabaya, 2018). Sedangkan obyek penelitian ini adalah Mitra10 Pasar Baru, Tangerang. Oleh karena itu, untuk menghasilkan opini atau alternative tersebut maka peneliti menggunakan metode penyebaran survey (angket) dengan tujuan agar bisa mendapatkan 
data-data yang dikelompokkan menjadi sebuah tabulasi data dan diolah menggunakan software SPSS agar mampu mendeskripsikan secara lebih dekat kepada informasi yang dihasilkan dari kuesioner tersebut. Data-data yang dikumpulkan melalui angket atau kuesioner tersebut tergolong dalam kelompok data utama (primer) yang proses pengumpulan datanya dimulai sejak Juli tahun 2020 dari para konsumen yang sudah membeli atau belum memutuskan membeli kebutuhan bahan bangunan dan sarana perkakas pada Mitra10 Pasar Baru Tangerang. Pengambilan 134 sampel diambil menggunakan prinsip aksidental.

Pada dasarnya pengelompokan yang terbentuk sangat begitu beragam, sehingga apa yang disampaikan sebelumnya bahwa didalam pengelompokan ini bisa saja mengkaitkan pada beberapa factor dan turunan factor (Muhidin, 2017)

yang dianggap mampu mewakili dari sebuah kategori pengelompokan yang tidak terlepas dari sebuah nilai yang dianut bagi sekelompok konsumen atau pelanggan yang melakukan pembelian atau sekedar melihat (belum terjadi keputusan pembelian) Segmentasi psikografis merupakan pembagian segmen pasar konsumen dengan memanfaatkan persepsi, gaya hidup, top of mind, dan nilai yang dianut pada suatu cakupan pasar konsumen. Pada proses segmentasi psikografis yang dilakukan dalam sebuah penelitian memerlukan kecukupan sebuah data yang bisa saja diperoleh dari cara cara yang sesuai dengan kaidah keilmuan seperti survey, hal ini bertujuan untuk mendapatkan sebuah gambaran mendekati realitas yang seringkali muncul didalam persepsi atau benak konsumen untuk memutuskan pembelian atau tidak (Setiadi, 2008). Oleh karena itulah peneliti melakukan pre feasibility terhadap komponen psikografis, dan merumuskan adanya enam belas variable yang dapat digunakan oleh para responden ketika berbelanja di Mitra10 Pasar Baru Tangerang, dimana keenam belas variable tersebut antara lain yaitu persepsi atas sebuah harga yang tidak mahal ketika berbelanja di Mitra10 (X1), banyak pilihan harga pada barang yang diminati (X2), beragamnya program diskon pada Mitra10 (X3), Kualitas Produk yang disediakan oleh Mitra10 (X4), Persepsi harga dimata konsumen (X5), Mitra10 menyiapkan merek yang cukup dikenal (X6), media promosi produk menggunakan artis (X7), Kebanggaan/prestise (X8), penggemar produk sejenis namun dari brand yang berbeda (X9), Penggunaan merek atas dasar rekomendasi (X10), penggunaan merek produk yang sudah lebih familiar (X11), niat membeli sewaktuwaktu (X12), membeli apa saja (X13), kebiasaan konsumen untuk membeli barang yang tidak sesuai rencana ketika tiba di Mitra10 (X14), ketergangungan pada daftar belanja sebelum ke Mitra10 (X15), dan melakukan analisa lanjutan untuk sebuah keputusan pembelian (X16). Sehingga untuk mendapatkan keeratan jawaban atas issue tersebut maka analisis klaster yang digunakan dianggap sesuai jika menggunakan metode hirarki. Metode yang digunakan dalam 
penelitian ini diharapkan mampu membentuk sebuah tree atau chart yang memiliki kekhususan didalam sebuah sifat indicator yang telah ditentukan sejak awal. Kemudian dapat dilanjutkan pada objek lainnya yang mempunyai kedekatan yang paling dekat dengan obyek pertama, dan demikian seterusnya sehingga dengan demikian proses pembentukan klaster akan mulai terbentuk dan menyerupai semacam tree yang memiliki tingkatan berdasarkan kedekatan kesamaan antar variable yang dihasilkan hingga rentang variable yang condong kontras berlawanan dengan obyek kemiripan. Pengklasteran yang dihasilkan melalui tahapan ini akan dapat dilihat dengan cara memasukkan dendogram didalam pengolahan lebih lanjut. Grafik Dendogram yang dihasilkan melalui sebuah penggabungan nilai dari proses pengolahan data dapat saja dianggap sebagai proses lanjutan pembentukan tree yang dilengkapi dengan nilai koefisien sehingga akan lebih memudahkan kita untuk memberikan interpretasi nilai yang diperoleh untuk menjawab hipotesis yang dimiliki dalam penelitian ini (Yulianto \& Hidayatullah, 2014).

\section{HASIL DAN PEMBAHASAN}

Berdasarkan atas data sampel yang diperoleh menggunakan prinsip aksidental, maka peneliti mendapatkan data sampel sebanyak 134 sampel baik yang hanya melakukan kunjungan dan pembelian di Mitra10 Pasar Baru Kota Tangerang yang dijadikan responden (sampel) maka selanjutnya adalah melakukan pengolahan data yang peneliti dapatkan selama mengunjungi obyek penelitian sejak bulan juli hingga agustus tahun 2020. Responden yang dijadikan sampel dalam penelitian ini diberikan kartu stimulant (angket) untuk mendapatkan gambaran atas jawaban yang diberikan atas sebuah pertanyaan dengan menggunakan skala likert dengan klasifikasi jawaban sebagai berikut 1 (sangat tidak setuju), 2 (tidak setuju), 3 (raguragu), 4 (setuju), 5 (sangat setuju).

selain itu menggunakan analisa klaster atau pengelompokkan konsumen dengan metode hirarki sebagai based awal dapat mampu memberikan sebuah simpulan mengenai segmentasi yang terbentuk. Dari keenam belas indicator atau variable yang dikembangkan kedalam factor segmentasi psikografis konsumen dari analisis yang dilakukan inilah dihasilkan setidaknya terdapat empat klasifikasi tingkatan konsumen Mitra10 yang dapat digolongkan berdasarkan kemiripan karakteristiknya terhadap kaitannya dengan sebuah persepsi yang terbentuk, diantaranya sebagai berikut :

Tabel 1. Descriptive Statistic

\begin{tabular}{|l|r|r|r|r|r|}
\hline \multicolumn{7}{|c|}{ Descriptive Statistics } \\
\hline & N & Minimum & Maximum & Mean & $\begin{array}{c}\text { Std. } \\
\text { Deviation }\end{array}$ \\
\hline Y1 & 16 & 59,00 & 87,00 & 74,3125 & 10,04469 \\
Y2 & 16 & 30,00 & 56,00 & 42,0000 & 9,10677 \\
Y3 & 16 & 7,00 & 16,00 & 11,5625 & 2,50250 \\
\hline Y4 & 16 &, 00 & 13,00 & 6,1250 & 4,50000 \\
\hline Valid N & 16 & & & & \\
(listwise) & & & & & \\
\hline
\end{tabular}

Pada tabel 1 diatas diketahui nilai rata-rata baik minimal, maksimal dan standar deviasinya masing-masing klaster. 
Tabel 2. Case Processing Summary

Cast Prustessing Summary"

\begin{tabular}{|r|r|r|r|r|r|}
\hline \multicolumn{9}{|c|}{ Cases } \\
\hline \multicolumn{2}{|c|}{ Valid } & \multicolumn{2}{|c|}{ Missing } & \multicolumn{2}{c|}{ Tolal } \\
\hline N & Percent & N & Percent & N & Percent \\
\hline 16 & 100.0 & 9 & .0 & IS & 190.9 \\
\hline
\end{tabular}

a. Murage Linkage (Bttwetu Gruups)

Pada tabel 2 diatas kita dapat melihat bahwa setidaknya hal ini sudah sesuai dalam hal tidak adanya satu indicator pun yang luput dalam pengolahan data.

Sedangkan tabel 3 yang mengenai matrix proximities menunjukkan jeda jarak yang dihasilkan antar indikator satu dengan indikator yang lain. selain itu kita bisa melihat jika jeda jarak yang dihasilkan semakin kecil maka hal ini dikatakan bahwa tingkat kemiripan antar variable tersebut semakin besar dan dapat membentuk bagian dari tree itu sendiri (klaster). 


\section{POINT}

\section{Jurnal Ekonomi dan Manajemen \\ e-ISSN : 2656-775X}

Tabel 3. Matrix Proximities

Proximity Matrix

\begin{tabular}{|c|c|c|c|c|c|c|c|c|c|c|c|c|c|c|c|c|}
\hline \multirow[t]{2}{*}{ Case } & \multicolumn{16}{|c|}{ Squariat Eustiotsan Distanfi: } \\
\hline & 1:X1 & $2: \times 2$ & $3 \times 3$ & $4: \times 4$ & $5: \times 5$ & fi: $X$ & $7: x$ & 8:X8 & $A \times 9$ & $[1]: X \mid 1]$ & $11: \times 11$ & $12: \times 12$ & $1.3 \times 1.3$ & $14: \times 14$ & $15 \times 15$ & $|f i X| f i$ \\
\hline $1: \times 1$ & ספספ. & 230.000 & 523.000 & DSL. & 8.000 & 178.000 & 45 & 694.000 & 523.000 & 542.000 & 158.000 & 170.000 & 政 2.9090 & 134.990 & 104.000 & 505.000 \\
\hline $2: \times 2$ & פ9פ.930 & .000 & 753.060 & 1158.990 & 270.000 & 34.500 & פפפ.950. & 1238.000 & 753.000 & 1158.000 & 54.000 & 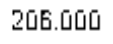 & 1170.990 & 209.929 & 98.060 & 545.000 \\
\hline $3: \times 3$ & ביפ & 756.002 & .000 & 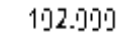 & 414.000 & 923000 & ניפנפינה & 110.000 & .000 & 102.000 & 634.020 & 2ŪE் Uับ̄Ū & 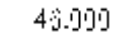 & 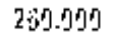 & 818.000 & 50.000 \\
\hline $4: \times 4$ & פפספ. & 1158.000 & 102.000 & פפפס. & 510.000 & 1233.000 & פפפס. & 8.000 & 102.000 & .000 & 914.000 & 464.000 & פפפ. ל & 434.990 & 1043.000 & 292.000 \\
\hline $5: \times 5$ & 8.90 & 270.000 & 414.006 & 510.90 & .000 & 238.060 & פפפ.950 & 554.000 & 414.000 & 510.000 & 186.000 & 134.000 & פ954.95. & פ11.9פ & 152.060 & 4.4 .000 \\
\hline $3: x_{i}$ & ניפנ. & 34.0020 & 920000 & 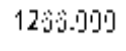 & 238.000 & .000 & ניפני. & 1358.0020 & 923.000 & 1256.000 & 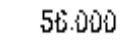 & 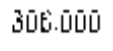 & 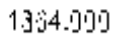 & $240.9 \mathrm{I}$ & 34.000 & 745.000 \\
\hline $7: X$ & 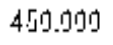 & 650.000 & 3.000 & פפספ.411 & 350.000 & 804.000 & ספספ. & 138.000 & 3.000 & 118.000 & 524.000 & 166.000 & פספ. פסם & 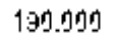 & 398.000 & 45.000 \\
\hline $8: x^{\prime}$ & פפפ.994. & 1238.000 & 110.006 & 8.990 & 554.000 & 1358. COCG & פפפ.938 & .000 & 110.000 & 8.000 & 10.14 .000 & 488.000 & פ9פ. & 595.999 & 1145.006 & 300.000 \\
\hline$d: X_{j}$ & פיפ. & $75 \mathrm{E} .0020$ & .000 & נפנפי.20 & 414.000 & 923000 & ניפניםני & 110.000 & .000 & 102.000 & 634.002 & 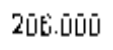 & ניפנ.j. & 26门.III & 818.000 & 50.000 \\
\hline $10: \times 10$ & פפפ. & 1158.000 & 102.000 & פפספ. & 510.000 & 1233.000 & פפספצ11 & 8.000 & 102.000 & .000 & 914.000 & 464.000 & פפפ.2ני & 434.990 & 1043.000 & 292.000 \\
\hline $11: \times 11$ & פפפ.98 & 54.000 & 334.006 & פפפ.914 & 186.000 & 53.000 & 524.990 & 10.14 .000 & 334.000 & 914.000 & .000 & 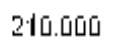 & פפפ. 194 & פפ. & 38.000 & 514.000 \\
\hline $12: \times 12$ & ניפני.17 & 201.002 & 2030.000 & נפנפ & 134.000 & 303.000 & ניפני.נ: 1 & 488.0002 & 203.000 & 454.000 & 210.0020 & (ŪŪŨ & 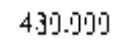 & 於.III & 302.000 & 118.000 \\
\hline $13: \times 13$ & פפg. & 1170.000 & 43.000 & ספפ. לי & 654.000 & 1334.000 & פספ. & 50.000 & 43000 & 52.000 & 1004.000 & 430.000 & פפפ. & 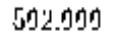 & 1210000 & 155.000 \\
\hline $14: \times 14$ & פפ.934 & 200.000 & 230.006 & פ934.934 & 110.000 & 245.000 & פפפ.90 & 506.000 & 230.000 & 434.000 & 90.000 & 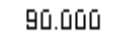 & 502.990 & פ9פ. & 170.006 & 230.000 \\
\hline $1.5: \times 1.5$ & נפ门ग & ต8.0บบ & 818.000 & 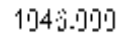 & 152.000 & 34.000 & כיפנים8 & 1146.0020 & 818.000 & 1045.000 & 38.000 & 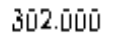 & ניפני.נ121 & 17. IIII & .000 & 718.000 \\
\hline $1 \ddot{1}: \times 1 \ddot{3}$ & פפספ. פני & 546.000 & 50.000 & פפפ. 292 & 414.000 & 743.000 & פפספ. צ4 & 300.000 & 50.000 & 292.000 & 514.000 & 116.000 & פפספ.לכ1 & פנפת. & 718.000 & .000 \\
\hline
\end{tabular}

This is a dissimilaritymatratix 
Tabel 4. Rata-Rata Jarak

\begin{tabular}{|c|c|c|c|c|c|c|}
\hline & \multicolumn{5}{|c|}{ Ayglomeration s: } & \multirow[b]{3}{*}{ Next Stagye } \\
\hline \multirow[t]{2}{*}{ Slage } & \multicolumn{2}{|c|}{ Clustor Combinas } & \multirow[b]{2}{*}{ Coetticients } & \multicolumn{2}{|c|}{ Stayl: Clusti:r First Anplu:ars } & \\
\hline & Cluster 1 & Cluster 2 & & Cluster $\mathbf{1}$ & Cluster 2 & \\
\hline 1 & 4 & 10 & . Ūūũ & 9 & $\overline{0}$ & 4 \\
\hline 2 & 3 & 9 & .000 & פ & 0 & 3 \\
\hline 3 & 3 & 7 & B. .000 & 2 & 0 & B \\
\hline 4 & 4 & 8 & ४.ūūū & 1 & 0 & 9 \\
\hline 5 & 1 & 5 & 8.000 & م & 0 & 12 \\
\hline دे & s & 15 & 34.000 & פ & 0 & 7 \\
\hline 7 & E & 11 & 47. ŪŨuั & ; & 0 & 10 \\
\hline 4 & 3 & 16 & 48.667 & 3 & 0 & 13 \\
\hline a & 4 & 13 & se.cuc & 4 & 0 & 13 \\
\hline 19] & 2 & ¿ & Eะ2.บ̄ū & 9 & 7 & 14 \\
\hline 11 & 12 & 14 & 90.000 & 9 & 0 & 12 \\
\hline 12 & 1 & 12 & 137.000 & 5 & 11 & 14 \\
\hline 1.3 & 3 & 4 & 139.บิบับั & s & 9 & 15 \\
\hline 14 & 1 & 2 & 202.873 & 12 & 10 & 15 \\
\hline 15 & 1 & 3 & 602.975 & 14 & 13 & 0 \\
\hline
\end{tabular}

Tabel 4 diatas menandakan bahwa proses klaterisasi dilakukan dengan menggunakan metode between group linkage dimana jeda jarak yang dihasilkan antar variable dikaitkan dengan jarak Euclidean, sehingga dengan demikian pengelompokan atau klaster yang dilakukan menyerupai sebuah tingkatan. Sebagai contoh tingkatan pertama membentuk sebuah klaster yang memiliki kesamaan dalam indicator no 4 dan 10 dengan koefisien signifikan hal ini terdapat pada kolom coefficients. Disamping itu untuk melengkapi proses aglomerasi maka bisa dimulai dari dua obyek yang memiliki kemiripan yang terdekat, sehingga bisa dikatakan bahwa jarak yang tergambarkan merupakan jarak yang memiliki besaran paling dekat dari sekian varian jarak keenam belas obyek dari indicator lainnya tersebut. Demikian pula ketika kita mengacu pada kolom next stage, terdapat angka empat, tentu saja hal ini mempunyai makna jika klater selanjutnya akan lebih baik dilakukan dengan melihat stage atau tingkatan indicator yang keempat. Dan demikian seterusnya bermula dari stage 4 proses dapat dilanjutkan ke stage berikutnya berdasarkan hasil pengolahan data, sampai pada bagian dimana sudah tidak mungkin lagi membentuk stage yang menjadi awal bagi stage selanjutnya.

Selanjutnya, adalah melakukan perhitungan koefisien yang dikenal sebagai proses aglomeraasi, proses yang memiliki komplekstisitas ini menggunakan kaitan obyek yang beragam sesuai dengan kebutuhan diawal (Nugroho, 2008). Proses aglomerasi yang dilakukan ini berujung pada penyatuan semua obyek untuk membentuk sebuah klaster (pengelompokan) utama, yang dalam prosesnya bisa saja menghasilkan jumlah klaster yang sepadan dengan jumlah keunikan yang muncul dari tiap indikatornya, dengan kata lain tergantung kepada jumlah klaster yang dapat dibentuk. (Johannes, 2004). Jumlah pengklasteran yang terbentuk dalam penelitian ini dapat merujuk pada tabel 5 berikut dibawah ini :

Tabel 5. Jumlah Klaster

\begin{tabular}{|l|r|r|r|r|r|r|}
\hline Faktor & \multicolumn{1}{|r|}{ Y1 } & \multicolumn{1}{|c|}{ Y2 } & \multicolumn{1}{|c|}{ Y3 } & \multicolumn{1}{|r|}{ Y4 } & \multicolumn{1}{c|}{ CLU4_1 } \\
\hline X1 & 67.00 & 50.00 & 16.00 & 1.00 & 1 \\
\hline X2 & 60.00 & 51.00 & 10.00 & 13.00 & 2 \\
\hline X3 & 81.00 & 34.00 & 11.00 & 8.00 & 3 \\
\hline X4 & 87.00 & 35.00 & 12.00 & .0 & 4 \\
\hline X5 & 69.00 & 48.00 & 16.00 & 1.00 & 1 \\
\hline X6 & 59.00 & 55.00 & 11.00 & 9.00 & 2 \\
\hline X7 & 80.00 & 36.00 & 10.00 & 8.00 & 3 \\
\hline X8 & 87.00 & 33.00 & 14.00 & .0 & 4 \\
\hline X9 & 81.00 & 34.00 & 11.00 & 8.00 & 3 \\
\hline X10 & 87.00 & 35.00 & 12.00 & .0 & 4 \\
\hline X11 & 65.00 & 53.00 & 7.00 & 9.00 & 2 \\
\hline X12 & 69.00 & 41.00 & 14.00 & 10.00 & 1 \\
\hline X13 & 86.00 & 30.00 & 12.00 & 6.00 & 4 \\
\hline X14 & 72.00 & 47.00 & 8.00 & 7.00 & 1 \\
\hline X15 & 63.00 & 56.00 & 10.00 & 5.00 & 2 \\
\hline X16 & 76.00 & 34.00 & 11.00 & 13.00 & 3 \\
\hline
\end{tabular}

Tabel diatas mempunyai deskripsi bahwa dari empat klaster yang terbentuk memiliki beberapa anggota didalamnya, sebagai contoh : 
Klaster 1 : terdapat indicator X1, X5, X12, X14

Klaster 2 : terdapat indicator X2, X6, X11, X15

Klaster 3 : terdapat indicator X3, X7, X9, X16, dan

Klater 4 : terdapat indicator X4, X8, X10, X13

Hal ini sangat sesuai dengan grafik Dendogram yang dihasilkan, grafik yang dihasilkan dapat dimanfaatkan untuk menunjukkan jumlah anggita yang ada, gambar 1 dibawah ini menggambarkan bentuk dendogram yang terbentuk, :

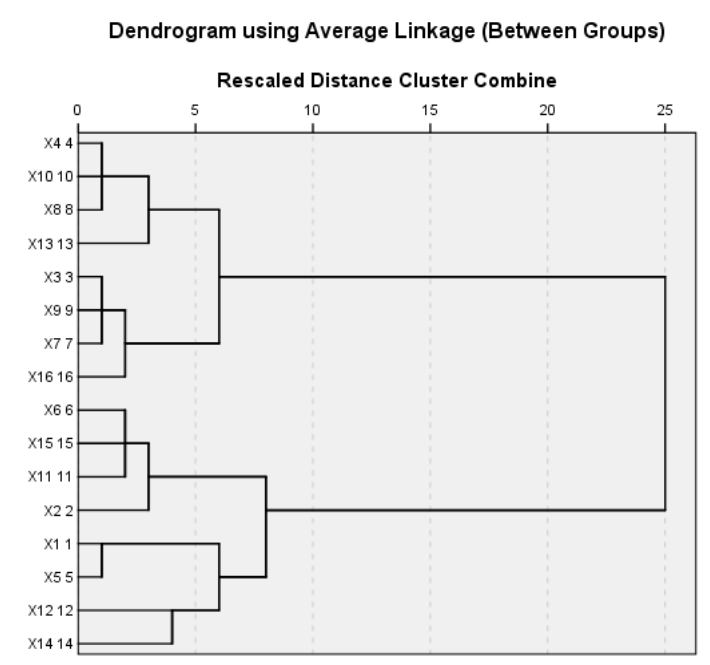

Gambar 1. Dendogram

Pada gambar diatas jika kita akan membuat dua pengelompokan (klaster), maka kelompok pertama beranggotakan indicator $\mathrm{X} 3, \mathrm{X} 4, \mathrm{X} 7, \mathrm{X} 8$, X9, X10, X13, X16 dan indicator lainnya masuk kedalam klaster 2 .

\section{PENUTUP}

\section{Kesimpulan}

Dari hasil olahan data diatas, setidaknya dapat disimpulkan bahwa secara garis besar konsumen yang datang ke Mitra10 Pasar Baru Tangerang adalah konsumen yang terklasifikasikan menjadi empat kelompok konsumen yang memiliki ciri kedekatan atas keunikan yang dimiliki indicator disetiap kelompoknya. Dari hasil pengolahan data yang dilakukan pula kita bisa memberikan secara garis besar bahwa segmentasi dari konsumen Mitra 10 Pasar Baru Tangerang sebagai berikut :

a. Kelompok pertama : kelompok ini mempunyai kedekatan ciri pada persepsi konsumen Mitra10 dimana para konsumen dalam kelompk pertama ini adalah konsumen yang lebih melihat pada indicator harga yang lebih murah, yang kemudian menimbulkan persepsi dimata konsumen bahwa harga yang diberikan masih ditingkat kewajaran jika dibandingkan dengan kualitas, konsumen tertarik atas promosi yang dilakukan dan cenderung membeli barang kebutuhan yang tidak sesuai rencana, karena di Mitra10 disediakan berbagai macam bahan bangunan dan perkakas yang menarik para konsumen untuk membeli diluar rencana pembelian yang telah dibuat.

b. Kelompok kedua : kelompok konsumen ditingkat/dilapisan kedua pada segmen ini mempunyai ciri kedekatan didalam persepsi konsumen yang melihat beragamnya daftar harga, terutama pada produk yang memiliki brand cukup dikenal, dan sudah digunakan sebelumnya oleh yang bersangkutan sehingga konsumen tersbeut membuat perencanaan akan datang kembali ke Mitra10 ketika produk yang biasa dipakai 
sudah mengalami kekurangan atau kerusakan (ganti baru).

c. Segmen 3 : segmen ini dicirikan oleh konsumen yang melihat beragamnya program diskon, terutama pada merekemerek tertentu, dengan pertimbangan tertentu dan atas dasar keingintahuan dari kegunaan barang yang dibeli.

d. Segmen 4 : segmen ini dicirikan oleh konsumen yang melihat bahwa produk yang disediakan di Mitra10 memang memiliki kualitas, sehingga menciptakan prestise sehingga menjadikan merek tersebut lebih familiar, dan memiliki kencendrungan untuk membeli lagi.

\section{Saran}

Dari simpulan yang diberikan diatas, peneliti dalam hal pembahasan segmentasi konsumen Mitra10 Pasar Baru Tangerang, ternyata dapat ditemui bahwa terdapat empat kelompok segmentasi dari 134 sampel dengan demikian manajemen Mitra10 dapat merumuskan kebijakan terkait targeting terutama pada kelompok dengan jumlah anggota klaster yang paling mendominasi seperti pada klaster 1, karena pada klaster 1 terlihat fenomena bahwa Mitra10 meksipun memberikan harga yang cukup tinggi, tapi masih dinilai wajar oleh para konsumen ketika disandingkan dengan kualitas dari produk yang dibelinya itu. Dengan melihat adanya kemungkinan factor yang muncul yang mempunyai pengaruh yang sama maka akan lebih baik jika dilakukan terlebih dahulu analisis factor yang mendominasi para konsumen untuk datang ke Mitra10 selain daripada keenam belas factor yang disampaikan dalam penelitan ini, sehingga dalam penelitian selanjutnya bisa dilakukan berbagai analisa yang mungkin dijadikan sebagai alternative lainnya dalam memberikan kebijakan yang tepat bagi manajamen Mitra10, seingga dapat memberikan tingkat optimal dalam mencapai tujuan perusahaan dan dapat memberikan strategi pertahanan pangsa pasar dalam masa pandemic global yang sedang dihadapi oleh seluruh dunia seperti saat ini.

\section{DAFTAR PUSTAKA}

Buku Edisi Karya:

Ahmadi, N. K., \& Herlina. (2017). Analisis Segmentasi Terhadap Keputusan Pembelian Produk Eiger di Bandar Lampung. Jurnal Manajemen Magister, Vol 03. No.01, Januari 2017.

Deviany Amanda Rizki, D. (2013). Analisis Persepsi Konsumen Dan Strategi Pemasaran Beras Analog (Analog Rice). Jurnal Manajemen Dan Organisasi, 144-162.

JOHANNES, S. (2004). ANALISIS MULTIVARIAT ARTI DAN INTERPRETASI. JAKARTA: PT. RINEKA CIPTA.

Ketherin, B. E., Arifiyanti, A. A., Sodik, A., \& Institut Teknologi Adhi Tama Surabaya. (2018). Analisa Segmentasi Konsumen Menggunakan Algoritma K-Means Clustering. Seminar Nasional Sains Dan Teknologi Terapan VI 2018.

Kotler, P., \& Armstrong, N. G. (2008). PrinsipPrinsip Pemasaran. Jakarta: Erlangga.

Malhotra. (2006). Riset Pemasaran Pendekatan Terapan. Jakarta: PT. Indeks Kelompok Gramedia.

mitra10_official. (2015, November 06). Mitra10 Company Profile. Jakarta, Jakarta, Indonesia.

Muhidin, A. (2017). Analisa Metode Hierarchical Clsutering dan K-Mean dengan Model LRFMP pada Segmentasi Pelanggan. SIGMA, Jurnal Teknologi Pelita Bangsa. 
Nugroho. (2008). Statistik Multivariat. Bengkulu: UNIB Press.

Prasetyo, L. D., Moniharapon, S., \& Loindong, S. (2017). PENGARUH FAKTOR-FAKTOR SEGMENTASI DEMOGRAFIS DAN SEGMENTASI PSIKOGRAFIS TERHADAP KEPUTUSAN PEMBELIAN PADA MATAHARI DEPARTMENT STORE MTC MANADO. Jurnal EMBA: Jurnal Riset Ekonomi, Manajemen, Bisnis Dan Akuntansi. https://doi.org/10.35794/emba.v5i2.16163 Setiadi. (2008). Perilaku Konsumen : Konsep dan Implikasi Untuk Strategi dan Penelitian Pemasaran. Jakarta: Kencana Prenada Media Group.

Trisnawati, E., Suroso, A., \& Kumorohadi, U. (2012). Analisis Faktor-Faktor Kunci Dari Niat Pembelian Kembali Secara Online (Study Kasus Pada Konsumen Fesh Shop). Jurnal Bisnis Dan Ekonomi (JBE).

Tohari, A. (2016). Cluster Analysis Psychographic Consumers Kediri Town Square. Jurnal Matematika Dan Pendidikan Matematika, 109-118.

Umar. (2000). Riset Pemasaran dan Perilaku Konsumen. Jakarta: Gramedia.

Yulianto, S., \& Hidayatullah, K. H. (2014). ANALISIS KLASTER UNTUK PENGELOMPOKAN KABUPATEN/KOTA DI PROVINSI JAWA TENGAH BERDASARKAN INDIKATOR KESEJAHTERAAN RAKYAT. Statistika, 56-63. 